\title{
Anti-Fatigue Effect of Blended Camellia oleifera Abel Tea Oil and Ge-132 in Mice
}

\author{
Lisong Hu, Xuezhi Fang, Menghao Du, Jingping Zhang \\ Research Institute of Subtropical Forestry, Chinese Academy of Forestry, Fuyang, China \\ Email: Lisohu@hotamil.com
}

Received 24 October 2015; accepted 21 November 2015; published 24 November 2015

Copyright (C) 2015 by authors and Scientific Research Publishing Inc.

This work is licensed under the Creative Commons Attribution International License (CC BY). http://creativecommons.org/licenses/by/4.0/

(c) (i) Open Access

\begin{abstract}
Nowadays, people are busier and busier for working and living, and suffer a lot of pressure on their body or mind. Therefore, people are prone to have fatigue activity and decrease their working efficiency and happiness. It was reported that fatigue is a common symptom in the community, with up to half of the general population complaining of fatigue. More and more researchers devoted themselves to studying natural active ingredients in organism as the anti-fatigue drugs to release fatigue symptom. However, these natural ingredients were difficult to obtain from plants, animals and microorganisms by separating and purifying. In addition, some active substances have many side effects. In our study, we employed tea seed oil as main ingredients blended with bis-(carboxyethylgermanium) sesquioxide (Ge-132) to investigate the effects of anti-fatigue on mice by administrating mice with low dose, intermediate dose and high dose of tea seed oil complex for 0,2 or 4 weeks. The specific tests of studying effects of anti-fatigue were body weight, weight-loaded force swimming, blood urea nitrogen, blood lactic acid and hepaticglycogen. And the results showed that appropriate level of tea seed oil complex could decrease the body weight and prolong the weight-loaded swimming time, and had an active effect on the bloodurea nitrogen, hepatic glycogen and blood lactic acid level mice, which significantly embodied the anti-fatigue activity of tea seed oil complex.
\end{abstract}

\section{Keywords}

Tea Seed Oil, Ge-132, Anti-Fatigue, Blending

\section{Introduction}

Fatigue is a common symptom in the community, with up to half of the general population complaining of fatigue in most surveys [1] [2]. Fatigue could be classified into 2 categories: physical fatigue and mental fatigue [3] 
[4], which could have a major impact on all aspects of life [5]-[7]. In the past few decades, health scholar and athletic physiologist have been looking for natural active ingredients to release the fatigue and accelerate the elimination of fatigue in human beings [8]. However, these natural ingredients are difficult to obtain from plants, animals and microorganisms by separating and purifying. In addition, some active substances have many side effects and are more expensive for daily use.

The tea seed oil (Camellia oleifera Abel) extracted or cold pressed from the seed of the tea plant, is well known as "oriental oil", which is widely used in south of China as edible oil, medicine and burning injury for thousands of years [9]-[11]. Due to its high abundant content of oleic acid, linoleic acid, linolenic acid, and palmitic acid, the tea seed oil has the similar fatty acids composition with olive oil [12]. The tea seed oil is applied as functional food and food supplementary to help patients reduce contents of cholesterol and triglycerides in blood [13] [14]. Zhang and Zhou et al. reported that tea oil had antioxidant ability against several degenerative pathologies, including cardiovascular diseases and cancer [15]. Moreover, the tea seed oil was shown to have an anti-obesity effect in vivo model [16]. Besides the main constituents of fatty acids, the tea oil still has some other bioactive components such as phenolic com-pounds, squalenes and so on [13] [17]. It is reported that phenolic compounds have strong anti-hypoxia and anti-fatigue abilities [18] [19]. However, little information has been devoted to the anti-fatigue effects of the tea seed oil.

Ge-132 is the most common and well studied organic germanium. Ge-132 has been reported to enhance several cytokines and release Chronic Epstein-Barr Epstein Barr Virus Syndrome [20]. Therefore, Ge-132 has been widely used as a dietary supplement and has preceded clinical trial with promising preclinical results as both an antiviral and anticancer agent [21]. The organogermanium compound biscarboxyethyl germanium sesquioxide has been found to provide relief for many patients from the of-ten-debilitating symptoms of the chronic Epstein-Barr virus syndrome [20] [22].

Our goal is to evaluate the effect of anti-fatigue activity of the complex of tea seed oil blended GE-132 in mice. And we could evaluate to human beings as daily supplementary for the next studying.

\section{Materials and Methods}

\subsection{Materials}

Tea seed oil from Camellia oleifera Abel was obtained by cold-press technique from Jiande Xiawu Agriculture Development Co., Ltd., Zhejiang, China.

Ge-132 was purchased from Qingdao New Research Nonferrous Metal Co., Ltd., Qingdao, China. Store at $4^{\circ} \mathrm{C}$ in refrigerator.

Tea seed oil complex: adding the tea seed oil and Ge-132, with the ratio of $(100: 1)$, at $30^{\circ} \mathrm{C}-70^{\circ} \mathrm{C}$ in a flask, the mixture was stirred fiercely with T25 digital ultra-turrax high-speed homogenizer, IKA Co., Germany, till the tea seed oil and Ge-132 distributed well and keep at $4^{\circ} \mathrm{C}$ in refrigerator.

Glycogen Assay Kit and Lactic acid Assay kit were purchased from Nanjing Jiancheng Bioengineering Institute. And Urea Assay kit was purchased in DiaSys Diagnostic Systems (Shanghai) Co., Ltd.

\subsection{Animals}

Weighing 18 - 20 g male imprinting control region (ICR) mice, 6 - 8 weeks of age using in this study were purchased from Shanghai Slac Laboratory Animal Co., Ltd., Shanghai, China. The male ICR mice were maintained in Specific Pathogen Free (SPF) Laboratory of Medical University of Zhejiang China. And the experimental procedure was conducted in strict adherence to animal care guidelines in compliance with the guide for the care and use of Laboratory Animals. All procedures involving animals were reviewed and approved by the institutional animal care of animal administration act of Zhejiang province (2009). The animal protocol was designed to minimize pain or discomfort to the animals.120 ICR mice were housed in SPF Laboratory maintained at $23^{\circ} \mathrm{C}$ $\pm 1^{\circ} \mathrm{C}, 50 \%-70 \%$ humidity and $150-200 \mathrm{Lx}$ intensity of light with a $12 \mathrm{~h}$ light/dark cycle. 120 mice were randomly divided to polycarbonate cages. 5 mice in each set allowed free access to eat and drink water. The water was filtered and sterilized. And the feed was radioactive by Co 60 to sterilize.

\subsection{Methods}

After being fed for 1 week, 120 ICR mice were divided into 4 groups randomly according to their body weights. 
Each group had 30 ICR mice. The dose levels per body weight $(\mathrm{g} / \mathrm{kg})$. The Control Group was used as the control during the study; Low dose group were administrated $0.5 \mathrm{~g} / \mathrm{kg} /$ day of tea seed oil complex; Intermediate dose group were administrated $1.0 \mathrm{~g} / \mathrm{kg} /$ day of tea seed oil complex; High dosage group were administrated 2.0 $\mathrm{g} / \mathrm{kg} / \mathrm{day}$ of tea seed oil complex. The control group was fed with $2 \%$ sucrose fatty acid esters aqueous solution. At 0 week, 2 weeks and 4 weeks, 10 ICR mice were selected randomly from each group to perform the weightloaded swimming test, blood urea nitrogen test, hepatic glycogen test and blood lactic acid test.

\subsection{Weight-Loaded Forced Swimming Test [23]}

After 30 minutes of the last oral administration, the forced swimming test was carried out in a water tank where mice had big enough room and no disturbance from other mice with Morris water maze system. The depth of water was more than $30 \mathrm{~cm}$, and the temperature was $25^{\circ} \mathrm{C} \pm 0.5^{\circ} \mathrm{C}$. A steel washer weighing approximately $5 \%$ of their body weight was attached to the tail. The mice swimming time was recorded till the mice drowned in water. During the whole swimming process, the mice should keep limb moving. If the mice did not move in water, the stick was employed to expel them moving.

\subsection{Blood Urea Nitrogen (BUN) Test [24]}

Thirty minutes after swimming without a load in $30^{\circ} \mathrm{C}$ water for 90 minutes and rest for 30 minutes, the mice were collected $0.5 \mathrm{~mL}$ of blood from eyeball. The blood was placed in $4^{\circ} \mathrm{C}$ refrigerators for $1 \mathrm{~h}$, and then centrifuged at rate of $3000 \mathrm{r} / \mathrm{min}$ for $10 \mathrm{~min}$. The serum was obtained from the treatment blood and stored for following use. Automatic biochemistry analyzer was employed to determine the urea contents in the serum of mice blood with the diacetylmonoxime method [25]. Urea reacted directly with diacetylmonoxime under strong acidic conditions to give a yellow condensation product. The reaction was intensified by the presence of ferric ions and thiosemicarbazide. The intense red color formed is measured at $540 \mathrm{~nm} /$ yellow green filter.

\subsection{Blood Lactic Acid (BLA) Test}

Thirty minutes after the last administration, the mice were forced to swim at $30^{\circ} \mathrm{C}$ for 30 min without load. Before swimming, $50 \mu \mathrm{L}$ of the mice blood was taken and added into $40 \mu \mathrm{L}$ breaking-cellular membrane liquid. The mixture was vibrated immediately; Twenty minutes after swimming, $20 \mu \mathrm{L}$ of the mice blood was taken from inner can thus and added into breaking-cellular membrane liquid and vibrated promptly. The area of lactic was calculated as follow:

$$
\begin{aligned}
\text { Area of lactic }= & 5 \times(\text { value of lactic acid before swimming } \\
& +3 \times \text { value of lactic acid at the moment of ending swimming } \\
& +2 \times \text { value of lactic acid after rest of } 20 \mathrm{~min}) .
\end{aligned}
$$

\subsection{Hepatic Glycogen Test (Anthrone Method) [26]}

Thirty minutes after being oral administrated, the mice were sacrificed. Their livers were taken out, rinsed with saline and dried by filtrate paper and quickly frozen in liquid nitrogen and kept at $-70^{\circ} \mathrm{C}$ until the analysis for glycogen content.

To $100 \mathrm{mg}$ of mouse liver tissue in a tube, $8 \mathrm{~mL}$ 10\% trichloroacetic acid (TCA) was added, and then homogenized for $1 \mathrm{~min}$. The crude homogenated was centrifuged at $3000 \mathrm{r} / \mathrm{min}$ for $30 \mathrm{~min}$ and the supernatant fluid was employed for the following test. $1 \mathrm{~mL}$ of the supernatant fluid added into the $10 \mathrm{~mL}$ of centrifuge tube in which $4 \mathrm{~mL}$ of $95 \%$ ethanol solution was added (each sample had 2 duplicates in order to get reliable results), was mixed adequately to have no interphase between the supernatant fluid and $95 \%$ ethanol solution, at room temperature overnight, till the precipitate formed completely. The mixture in tube was centrifuged at $3000 \mathrm{r} / \mathrm{min}$ for $15 \mathrm{~min}$, decanted the supernatant and turned the tube upside down for $10 \mathrm{~min}$ to remove off the excessive fluid. Then, distilled water was added into the tube to fully dissolve the precipitate in the tube. $2 \mathrm{~mL}$ of distilled water in the centrifuge tube was used as blank sample. The standard tube was prepared as follow: $10 \mathrm{~mL}$ anthrone reagent was added into the tube with $10 \mathrm{~mL}$ glucose standard solution and $1.5 \mathrm{~mL}$ distilled water. $10 \mathrm{~mL}$ anthrone reagent was added to the sample tube and cooled with cold water for $15 \mathrm{~min}$. All of the samples tubes 
were immersed in boiling water for $15 \mathrm{~min}$, and then cooled to room temperature in cold water bath. The hepatic glycogen contents were determined through spectrophotometry at $620 \mathrm{~nm}$.

\subsection{Statistical Analysis}

Data were analyzed using SPSS 11.5 version (SPSS Inc., Chicago, IL, USA). The results were demonstrated as the mean \pm SD. The significance of the mean difference between the control groups and each treatment groups was performed by one-way AVOVA test. The level of $\mathrm{p}<0.05$ was considered to be significant difference.

\section{Results}

\subsection{Effects of Tea Seed Oil Complex on the Body Weight of Mice}

As shown in Figure 1, when mice were administrated with $0.5,1.0$ and $2.0 \mathrm{~g} / \mathrm{kg} / \mathrm{day}$ of tea seed oil complex, the body weight of mice decreased more or less. Compared to the control group, administrated with low dosage of tea seed oil, body weights of mice were significantly decreased $(p<0.05)$. When the mice were administrated 4 weeks, compared to the control, all body weight of groups of the mice had significant decreased $(\mathrm{p}<0.05$, or $\mathrm{p}$ $<0.01)$.

\subsection{Effects of Tea Seed Oil Complex on Weight-Loaded Swimming Test in Mice}

The effects on swimming time were assessed, and the results were shown in Figure 2. The mice loaded with 5\% body weight load were administrated with control, $0.5 \mathrm{~g} / \mathrm{kg} / \mathrm{day}, 1.0 \mathrm{~g} / \mathrm{kg} / \mathrm{day}$ and $2.0 \mathrm{~g} / \mathrm{kg} / \mathrm{day}$ tea seed oil respectively. As a result, the intermediate dose group and high dose group showed a significant increase in swimming time to exhaustion compared to the control group after administrating with tea seed oil complex for 4 weeks. However, swimming time in $0.5 \mathrm{~g} / \mathrm{kg} /$ day group was $787.4 \pm 163.1 \mathrm{~min}$ and there was no difference (p > $0.05)$.

\subsection{Effects of Tea Seed Oil Complex on BUN in Mice}

BUN is the metabolic outcome of protein and amino acid. Urea formed in the liver and is carried by the blood to the kidneys for excretion. And urea nitrogen concentration in the blood can be used as the indication of renal function. As shown in Figure 3, compared to control all groups of mice of the BUN value decreased after exercise 4 weeks, especially the intermediate and the high dose groups were significant lower $(\mathrm{p}<0.05$ or $\mathrm{p}<0.01)$

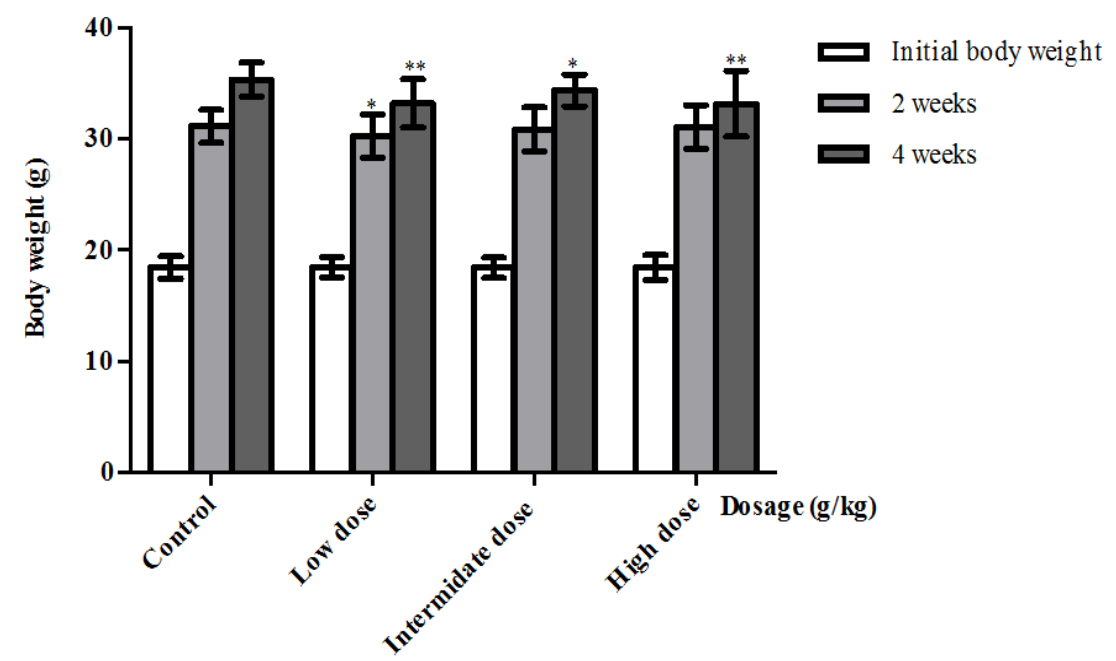

Figure 1. Effects of tea seed oil complex on weight-loaded swimming test in mice. The control group was administrated with $2 \%$ sucrose fatty acid esters aqueous solution; low dose group was administrated tea seed oil complex $(0.5 \mathrm{~g} / \mathrm{kg} / \mathrm{day})$; intermediate dosage group was administrated for tea seed oil complex $(1.0 \mathrm{~g} / \mathrm{kg} / \mathrm{day})$; high dose group was administrated tea seed oil complex ( $2.0 \mathrm{~g} / \mathrm{kg} / \mathrm{day})$. 


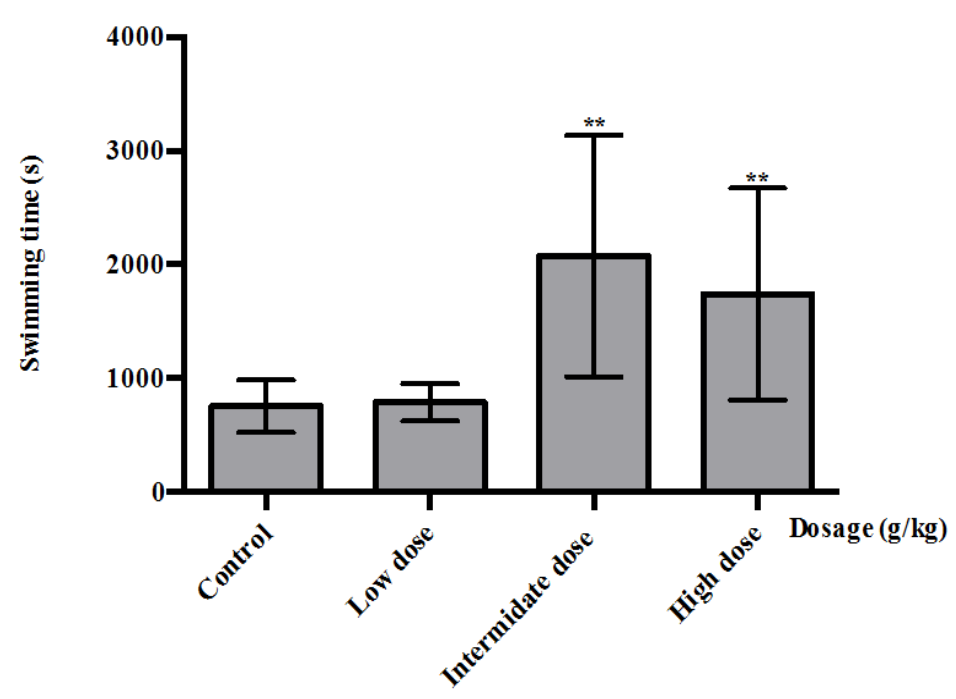

Figure 2. Effects of tea seed oil complex on weight-loaded swimming test in mice. The control group was administrated with $2 \%$ sucrose fatty acid esters aqueous solution; low dose group was administrated tea seed oil complex ( $0.5 \mathrm{~g} / \mathrm{kg} /$ day); intermediate dosage group was administrated for tea seed oil complex $(1.0 \mathrm{~g} / \mathrm{kg} / \mathrm{day})$; high dose group was administrated tea seed oil complex ( $2.0 \mathrm{~g} / \mathrm{kg} /$ day $)$.

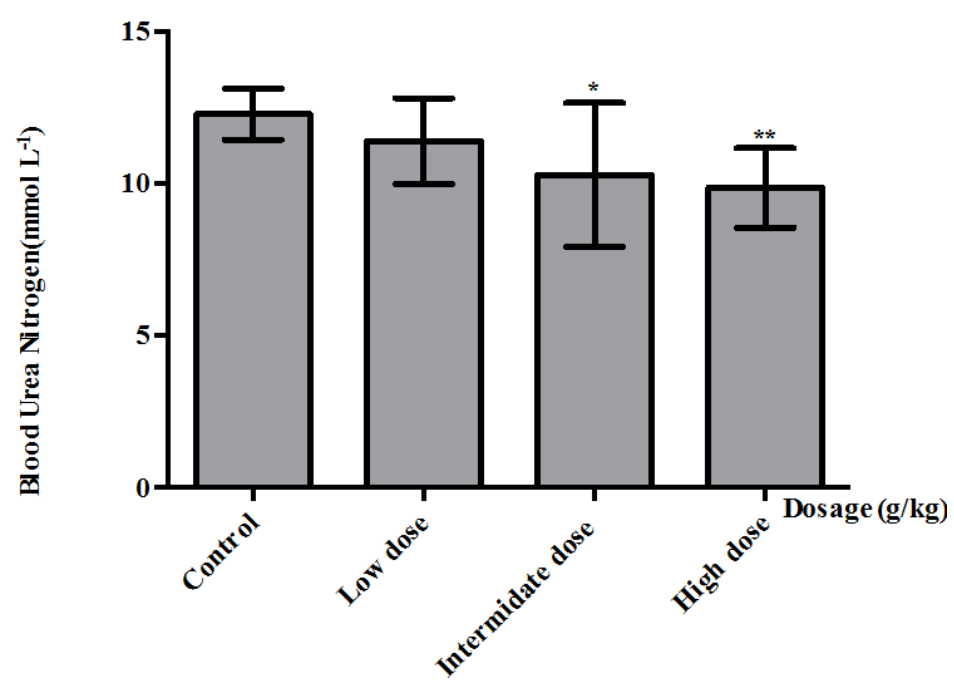

Figure 3. Effects of tea seed oil complex on BUN in mice. The control group was administrated with $2 \%$ sucrose fatty acid esters aqueous solution; low dose group was administrated tea seed oil complex $(0.5 \mathrm{~g} / \mathrm{kg} /$ day); intermediate dosage group was administrated for tea seed oil complex (1.0 g/kg/day); high dose group was administrated tea seed oil complex $(2.0 \mathrm{~g} / \mathrm{kg} /$ day $)$.

than the control group. The low dose of group was lower than the control group, but there were no significant differences $(\mathrm{p}>0.05)$.

\subsection{Effects of Tea Seed Oil Complex on BLA after Exercising in Mice}

Blood lactate is the glycolysis product of carbohydrate under an anaerobic condition, and glycolysis is the main energy source for fierce exercise in a short time. Therefore, blood lactate is closely related to workload intensity and is one of the important indicators for judging the intensity of the exercise and the condition of recovery. As 
shown in Figure 4, before exercising, all dose of the groups of contents of BLA decreased significantly compared to the control group. And as the dosage of tea seed oil complexes of low group, the both of swimming time and 20 minutes after, the contents of BLA also decreased significantly.

\subsection{Effects of Tea Seed Oil Complex on Hepatic Glycogen in Mice}

As shown in Figure 5, liver and muscle glycogen contents of the high dose group were significantly higher than that of the control group. However, the low-dose group and the intermediate group had the trend of increasing, but they have no significant difference $(p>0.05)$ compared with the control, after giving low dose, intermediate dose and high dose of tea seed oil for 4 weeks, the high dose group $(2.0 \mathrm{~g} / \mathrm{kg} /$ day tea seed oil) could significantly

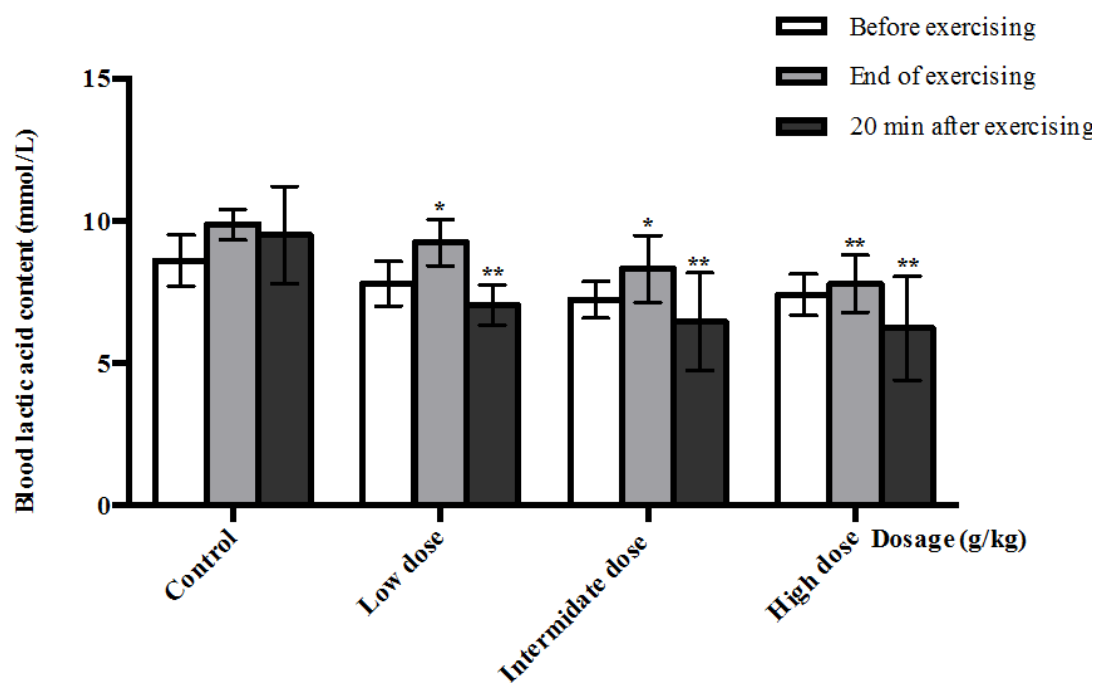

Figure 4. Effects of the tea seed oil complex on BLA after exercising in mice. The control group was administrated with $2 \%$ sucrose fatty acid esters aqueous solution; low dose group was administrated tea seed oil complex $(0.5 \mathrm{~g} / \mathrm{kg} /$ day $)$; intermediate dosage group was administrated for tea seed oil complex $(1.0 \mathrm{~g} / \mathrm{kg} /$ day); high dose group was administrated tea seed oil complex $(2.0 \mathrm{~g} / \mathrm{kg} /$ day $)$.

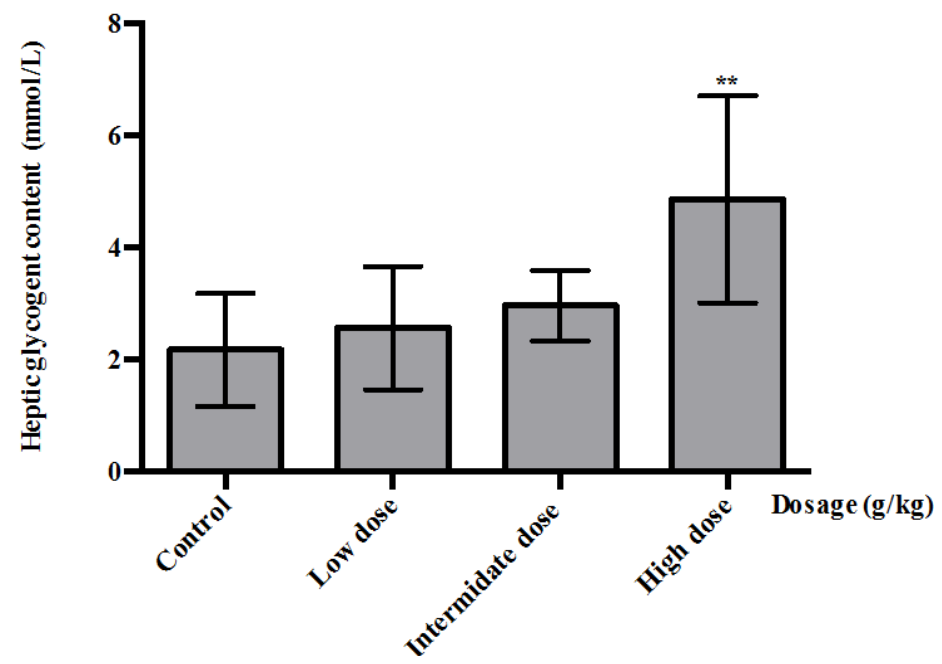

Figure 5. Effects of tea seed oil complex on hepatic glycogen in mice. The control group was administrated with $2 \%$ sucrose fatty acid esters aqueous solution; low dose group was administrated tea seed oil complex ( $0.5 \mathrm{~g} / \mathrm{kg} /$ day); intermediate dosage group was administrated for tea seed oil complex $(1.0 \mathrm{~g} / \mathrm{kg} / \mathrm{day})$; high dose group was administrated tea seed oil complex $(2.0 \mathrm{~g} / \mathrm{kg} /$ day $)$. 
increase the contents of hepatic glycogen $(p<0.01)$; the low and intermediate group also have the trend of increase $(\mathrm{p}>0.05)$.

\section{Discussions}

In this study, the mice were allocated to 4 groups (control, low dose, intermediate dose and high dose), according to the administration. The high dose group of mice had significant differences compared to the control group. Our results demonstrated that tea seed oil and Ge-132 complex had better effects on the mice of losing weight. The reason is that tea seed oil contained polyphenolic compounds blended with Ge-132 could enforce their effects.

The improvement of exercise endurance is a direct evidence of improving anti-fatigue ability. Swimming time reflects the degree of fatigue of animal [27]. Herein, the procedure used in our test was similar to that described previously [28]. The forced swimming test commonly used in anti-fatigue and endurance, has been used extensively for the evaluation of the anti-fatigue properties. In our study, the data showed that administration of tea seed oil complex could obviously prolong the mice swimming time. Tea seed oil had anti-fatigue activity and could elevate the exercise tolerance. Our results showed that different dosage of tea seed oil complex especially intermediate group and high dosage group could significantly prolong the swimming time of mice.

Energy for exercise is derived initially from breakdown of glycogen. After strenuous exercise muscle glycogen will be exhausted. Later, from circulating glucose released by the liver. So liver and muscle glycogen are sensitive parameters related to fatigue [29]-[31]. The data mentioned above revealed that the content of liver and muscle glycogen of mice in tea seed oil were higher than control group after swimming. However the detailed mechanism isn't clear. The possible reason is that camellia complex may increase the content of liver and muscle glycogen of mice post exercise by improving glycogen reserve, or by reducing the consume of glycogen during exercise, or both. It still needs the further studies.

BUN is the metabolism outcome of protein and amino acid. Urea is formed in the liver as the end product of protein-metabolism and is carried by the blood to the kidneys for excretion. Protein and amino acids have a stronger catabolic metabolism when body cannot obtain enough energy by sugar and fat carbolic metabolism, after a long time of movement, urea nitrogen obviously increase at this time. There is a positive correlation between the urea nitrogen in vivo and exercise tolerance. In other words, the worse the body is adapting for exercise tolerance, the more significantly. In our study, the tea seed oil complex demonstrated good ability of decreasing BUN in mice.

Serum urea nitrogen and blood lactic acid are important blood biochemical parameters related to fatigue. Urea is formed in the liver as the end of product of protein-metabolism. During digestion, protein is broken down into amino acids. There is a correlation between the urea nitrogen in vivo and the exercise tolerance [32]. In our experiments, the blood lactic acid of intermediate and high dosage of tea seed oil complex groups was lower than that of control group after swimming. The results suggest that tea seed oil complex can inhibit the production of blood lactic acid during exercise load increasing. Our results showed the trend that serum BUN of the low, intermediate and high dose intervention groups were lower than control group. In addition, our study also showed that low dose tea seed oil complex can increase hemoglobin of mice.

Hepatic glycogen for prolonged exercise has been studied for many years [33]-[35]. After the swimming to exhaustion, compared to the control group, the high dose group had significant difference. And all group increased their hepatic glycogen content. The results show that the tea seed oil complex was beneficial for improving the hepaticglycogen content.

\section{Conclusion}

In conclusion, our results suggest that tea seed oil complex had significant anti-fatigue effects on mice and these effects were dose-dependent; when dosage was high, it normally would improve the effects much better, especially on BUN test and hepatic glycogen test.

\section{Acknowledgements}

The authors are gratefully for the support given by Yalin Shenwu Co., Ltd. We also gratefully acknowledge Dongbing Zhang for providing us lab assistance. This work was supported by the project of Science and Tech- 
nology Department of Zhejiang Province, China (2014C32122).

\section{Conflict of Interests}

The authors declare that they have no competing interests.

\section{References}

[1] Afari, N. and Buchwald, D. (2003) Chronic Fatigue Syndrome: A Review. The American Journal of Psychiatry, 31, 167-194. http://dx.doi.org/10.1176/appi.ajp.160.2.221

[2] Pawlikowska, T., Chalder, T., Hirsch, S.R., Wallace, P., Wright, D.J.M. and Wessely, S.C. (1994) Population Based Study of Fatigue and Psychological Distress. BMJ, 308,763-766. http://dx.doi.org/10.1136/bmj.308.6931.763

[3] Chen, J.R., Wang, T.J., Huang, H.Y., Chen, L.J., Huang, Y.S., Wang, Y.J. and Tseng, G.F. (2009) Fatigue Reversibly Reduced Cortical and Hippocampal Dendritic Spines Concurrent with Compromise of Motor Endurance and Spatial Memory. Neuroscience, 161, 1104-1113. http://dx.doi.org/10.1016/j.neuroscience.2009.04.022

[4] Akazawa, K.H., Cui, Y., Tanaka, M., Kataoka, Y., Yoneda, Y. and Watanabe, Y. (2010) Mapping of Regional Brain Activation in Response to Fatigue-Load and Recovery in Rats with c-Fosimmunohistochemistry. Neuroscience Research, 66, 372-379. http://dx.doi.org/10.1016/j.neures.2009.12.009

[5] Webster, D.M., Richter, L. and Kruglanski, A.W. (1996) On Leaping to Conclusions When Feeling Tired: Mental Fatigue Effects on Impressional Primacy. Journal of Experimental Social Psychology, 32, 181-195.

http://dx.doi.org/10.1006/jesp.1996.0009

[6] Negahban, H., Etemadi, M., Naghibi, S., Emrani, A., Yazdi, M.J.S., Salehi, R. and Bousari, A.M. (2013) The Effects of Muscle Fatigue on Dynamic Standing Balance in People with and without Patellofemoral Pain Syndrome. Gait \& Posture, 37, 336-339. http://dx.doi.org/10.1016/j.gaitpost.2012.07.025

[7] Barbieri, F.A., Lee, Y.J., Gobbi, L.T.B., Pijnappels, M. and Van Dieën, J.H. (2013) The Effect of Muscle Fatigue on the Last Stride before Stepping Down a Curb. Gait \& Posture, 37, 542-546. http://dx.doi.org/10.1016/j.gaitpost.2012.09.015

[8] Kim, K.M., Yu, K.W., Kang, D.H., Koh, J.H., Hong, B.S. and Suh, H.J. (2001) Anti-Stress and Anti-Fatigue Effects of Fermented Rice Bran. Bioscience, Biotechnology and Biochemistry, 65, 2294-2296. http://dx.doi.org/10.1271/bbb.65.2294

[9] Zhang, L.L., Wang, Y.M., Wu, D.M., Xu, M. and Chen, J.H. (2010) Comparisons of Antioxidant Activity and Total Phenolics of Camellia oleifera Abel Fruit Hull from Different Regions of China. Journal of Medicinal Plants Research, 4, 1407-1411.

[10] Shao, P., Liu, Q., Fang, Z. and Sun, P. (2015) Chemical Composition, Thermal Stability and Antioxidant Properties of Tea Seed Oils Obtained by Different Extraction Methods: Supercritical Fluid Extraction Yields the Best Oil Quality. European Journal of Lipid Science and Technology, 117, 355-365. http://dx.doi.org/10.1002/ejlt.201400259

[11] Sahari, M. and Amooi, M. (2013) Tea Seed Oil: Extraction, Compositions, Applications, Functional and Antioxidant Properties. Academia Journal of Medicinal Plants, 1, 68-79.

[12] Sahari, M., Ataii, D. and Hamedi, M. (2004) Characteristics of Tea Seed Oil in Comparison with Sunflower and Olive Oils and Its Effect as a Natural Antioxidant. Journal of the American Oil Chemists' Society, 81, 585-588. http://dx.doi.org/10.1007/s11746-006-0945-0

[13] Lee, C.P. and Yen, G.C. (2006) Antioxidant Activity and Bioactive Compounds of Tea Seed (Camellia oleifera Abel.) Oil. Journal of Agricultural and Food Chemistry, 54, 779-784. http://dx.doi.org/10.1021/jf052325a

[14] Fedeli, E., Lanzani, A., Capella, P. and Jacini, G. (1966) Triterpene Alcohols and Sterols of Vegetable Oils. Journal of the American Oil Chemists' Society, 43, 254-256. http://dx.doi.org/10.1007/BF02641098

[15] Zhang, B. and Zhou, Y. (1995) Effects of Tea Seed Oil and Soybean Oil on Oxygen Radical and Activities of Antioxidative Enzymes in Rat. Acta Nutrimenta Sinica, 17, 1432-1338.

[16] Kim, N.H., Choi, S.K., Kim, S.J., Moon, P.D., Lim, H.S., Choi, I.Y., Na, H.J., An, H.J., Myung, N.Y., Jeong, H.J., Um, J.Y., Hong, S.H. and Kim, H.M. (2008) Green Tea Seed Oil Reduces Weight Gain in C57BL/6J Mice and Influences Adipocyte Differentiation by Suppressing Peroxisome Proliferator-Activated Receptor- $\gamma$. Pflügers Archiv European Journal of Physiology, 457, 293-302. http://dx.doi.org/10.1007/s00424-008-0537-y

[17] Kähkönen, M.P., Hopia, A.I., Vuorela, H.J., Rauha, J.-P., Pihlaja, K., Kujala, T.S. and Heinonen, M. (1999) Antioxidant Activity of Plant Extracts Containing Phenolic Compounds. Journal of Agricultural and Food Chemistry, 47, 3954-3962. http://dx.doi.org/10.1021/jf9901461

[18] Wu, C., Chen, R., Wang, X.S., Shen, B., Yue, W. and Wu, Q. (2013) Antioxidant and Anti-Fatigue Activities of Phe- 
nolic Extract from the Seed Coat of Euryale ferox Salisb and Identification of Three Phenolic Compounds by LC-ESIMS/MS. Molecules, 18, 11003-11021. http://dx.doi.org/10.3390/molecules180911003

[19] Chen, M., Meng, H., Zhao, Y., Chen, F. and Yu, S. (2015) Antioxidant and in Vitro Anticancer Activities of Phenolics Isolated from Sugar Beet Molasses. BMC Complementary and Alternative Medicine, 15, 313. http://dx.doi.org/10.1186/s12906-015-0847-5

[20] Faloona, G.R. and Levine, S.A. (1988) The Use of Organic Germanium in Chronic Epstein-Barr Virus Syndrome (CEBVS). Journal of Orthomolecular Medicine, 3, 29-31.

[21] Brutkiewicz, R.R. and Suzuki, F. (1986) Biological Activities and Antitumor Mechanism of an Immunopotentiating Organogermanium Compound, Ge-132 [Review]. In Vivo (Athens, Greece), 1, 189-203.

[22] Straus, S.E., Tosato, G., Armstrong, G., Lawley, T., Preble, O.T., Henle, W., Davey, R., Pearson, G., Epstein, J.A.Y., Brus, I. and Blaese, R.M. (1985) Persisting Illness and Fatigue in Adults with Evidence of Epstein-Barr Virus Infection. Annals of Internal Medicine, 102, 7-16. http://dx.doi.org/10.7326/0003-4819-102-1-7

[23] Zhang, Y., Yao, X., Bao, B. and Zhang, Y. (2006) Anti-Fatigue Activity of a Triterpenoid-Rich Extract from Chinese Bamboo Shavings (Caulis bamfusae in Taeniam). Phytotherapy Research, 20, 872-876. http://dx.doi.org/10.1002/ptr.1965

[24] You, L., Zhao, M., Regenstein, J.M. and Ren, J. (2011) In Vitro Antioxidant Activity and in Vivo Anti-Fatigue Effect of Loach (Misgurnus anguillicaudatus) Peptides Prepared by Papain Digestion. Food Chemistry, 124, 188-194. http://dx.doi.org/10.1016/j.foodchem.2010.06.007

[25] Moore, R. and Kauffman, N. (1970) Simultaneous Determination of Citrulline and Urea Using Diacetylmonoxime. Analytical Biochemistry, 33, 263-272. http://dx.doi.org/10.1016/0003-2697(70)90296-4

[26] Van Der Vies, J. (1954) Two Methods for the Determination of Glycogen in Liver. Biochemical Journal, 57, 410-416. http://dx.doi.org/10.1042/bj0570410

[27] Wakayoshi, K., Yoshida, T., Udo, M., Kasai, T., Moritani, T., Mutoh, Y. and Miyashita, M. (1992) A Simple Method for Determining Critical Speed as Swimming Fatigue Threshold in Competitive Swimming. International Journal of Sports Medicine, 13, 367-371. http://dx.doi.org/10.1055/s-2007-1021282

[28] Koh, J.H., Kim, K.M., Kim, J.M., Song, J.C. and Suh, H.J. (2003) Anti-Fatigue and Antistress Effect of the Hot-Water Fraction from Mycelia of Cordyceps sinensis. Biological and Pharmaceutical Bulletin, 26, 691-694. http://dx.doi.org/10.1248/bpb.26.691

[29] Terjung, R., Baldwin, K., Winder, W. and Holloszy, J. (1974) Glycogen Repletion in Different Types of Muscle and in Liver after Exhausting Exercise. American Journal of Physiology Legacy Content, 226, 1387-1391.

[30] Ivy, J.L. (1991) Muscle Glycogen Synthesis before and after Exercise. Sports Medicine, 11, 6-19. http://dx.doi.org/10.2165/00007256-199111010-00002

[31] Costill, D., Coyle, E., Dalsky, G., Evans, W., Fink, W. and Hoopes, D. (1977) Effects of Elevated Plasma FFA and Insulin on Muscle Glycogen Usage during Exercise. Journal of Applied Physiology, 43, 695-699.

[32] Lee, B., Yu, H., Jahoor, F., O’Brien, W., Beaudet, A.L. and Reeds, P. (2000) In Vivo Urea Cycle Flux Distinguishes and Correlates with Phenotypic Severity in Disorders of the Urea Cycle. Proceedings of the National Academy of Sciences of the United States of America, 97, 8021-8026. http://dx.doi.org/10.2165/00007256-199111010-00002

[33] Wilber, C.G. (1959) Some Factors Which Are Correlated with Swimming Capacity in Guinea Pigs. Journal of Applied Physiology, 14, 199-203.

[34] Dohm, G.L., Tapscott, E.B., Barakat, H.A. and Kasperek, G.J. (1983) Influence of Fasting on Glycogen Depletion in Rats during Exercise. Journal of Applied Physiology, 55, 830-833.

[35] Favier, R. and Koubi, H. (1988) Metabolic and Structural Adaptations to Exercise in Chronic Intermittent Fasted Rats. American Journal of Physiology-Regulatory, Integrative and Comparative Physiology, 254, 877-884. 